\title{
Intensifying embroilments: Technosciences, imaginaries and publics
}

\author{
Luigi Pellizzoni \\ Department of Political and Social Sciences, University of Trieste \\ Piazza Europa 1, 34127 Trieste, Italy \\ luigi.pellizzoni@dispes.units.it
}

In: Public Understanding of Science, 26(2), 2017, special issue Imagining public issues in the technosciences, edited by Kjetil Rommetveit and Brian Wynne

Post-print version

\begin{abstract}
A common thread in the contributions to this special issue can be found in the Foucauldian notion of intensification. Technoscientific imaginaries and publics have long been embroiled, yet elements of novelty in their relationship can be detected in the ambivalence of the overcoming of traditional purification work, the expanding production of 'prototypical' truths, the uncertain threshold between publics of enquirers, witnesses and lookouts, and the growing indistinction of the everyday and the sublime, of trivial and non-trivial futures. The intensification of old patterns and recent trends determines a critical moment in a literal sense of the word: novel potentialities for a democratic governance of technosciences are opening up, but novel dominative opportunities are disclosing as well.
\end{abstract}

Keywords: governance of science and technology, technoscientific imaginaries, public participation, Foucault and intensification, indeterminacy, material turn, Dewey, future

\section{Introduction}

After reading the contributions to this special issue the feeling is not only that they contain more questions than answers (usually a good sign for exploratory enquiries), but also that the picture they outline is quite nuanced. If a common thread can be found, I would say it is captured by a concept that Michel Foucault applied in his works on governmentality: intensification.

Jeffrey Nealon effectively synthesizes the point about it. For Foucault, he notes, the emergence of new modes of power is not so much a matter of sudden changes, as of 'the lightening, saturation, becoming-more-efficient, and transversal linkage of existing practices [...] [up to] tipping points [...] where the object or subject mutates into another form' (2008: 38-39). In other words, gradual sliding in sense-making and practices engenders eventual qualitative shifts, the terms of which are however difficult to grasp precisely for this reason- things look similar, yet also different to what they used to be. 
If one reads through the preceding pages, it is actually hard to talk of anything radically new about technoscientific imaginaries and publics- what these are, how they relate to, or coproduce, each other. Yet, compared to even a recent past, the intensification of certain traits makes things perceptibly different. This emerges many times, together with the difficulty to specify the precise character of changes. That the socio-technical transformations triggered by post-Fordist capitalism and neoliberal regulation play a major role - not as a unidirectional influence (either of technosciences on renewed accumulation processes or of neoliberal governmentality on the reshaping of scientific research and technology development), but as an entanglement - is an explicitly or implicitly shared claim. In this framework, I believe, intensification can be a useful interpretive category. I will organize my reflections in three parts, according to the analytical distinction between the three issues at stake: technosciences, the public, and imagination.

\section{After purity}

As Rommetveit and Wynne remark, there seems to be growing acknowledgment and acceptance that science, technology and social order are embroiled in one another and, as a consequence, that their legitimacy does not stem anymore from a work of purification and distinction between the natural and the human. However, this does not seem necessarily to entail more harmonious or less dominative socio-material relationships.

A first note is that the normative ideal of the technological fix is well alive and that technosciences keep on imposing prescriptive social models. This is evident in Jepsen and Bertilsson's discussion of cochlear implantation (CI), as traversed by two opposed narratives supporting different imaginaries and related programs: on one side $\mathrm{CI}$ as a technological advancement effectively addressing a major disability; on the other, $\mathrm{CI}$ as assuming and imposing the figure of the deaf as an individual subject struggling for a full access to social life, in this way disregarding relations and identities pertaining to a distinctive cultural and linguistic community. Yet, promissory and prescriptive imaginaries are clearly at work also in the cases of in vitro meat and biometric profiling, and perhaps also in the demonstrative actions of bio and e-waste hackers, to the extent that they encourage not only creativity but also imitation.

Secondly, nondualist perspectives seem unable, in and by themselves, to promote any alternative model of society and socio-material relations. Latour (2004) has famously criticized the deconstructive modalities with which STS and he himself have long been associated, yet today the problem seems rather to lie in the nondualist outlook of which an influential example is represented by his own case for replacing matters of facts (or social constructions) with matters of concern, of contingent human-nonhuman gatherings. Nondualist ontologies often support post-humanist cases for humbleness and restraint vis-à-vis a lively materiality and ensuing non-dominative social relations, yet, they can be found as well at the basis of transhumanist cases for brave new worlds of technological answers to any problem or demand, in the framework of strongly capitalist agendas. This ambivalence penetrates the writings of individual authors - an example, in my opinion, is a recent book of Rosi Braidotti (2013) - yet it is possibly exemplified with the greatest evidence by the Ecomodernist Manifesto (Asafu-Adjaye et al. 2015), with which a group of scholars affiliated to the Breakthrough Institute (a think tank of neoliberal inspiration) ${ }^{1}$ make a case for a

\footnotetext{
${ }^{1}$ Describing the Breakthrough Institute as neoliberal seems accurate, given its argument about the 'planning fallacy' of Keynesian liberalism and its case for market-driven innovation within a regulatory framework ensured by institutions like the WTO, the World Bank and the International Monetary Fund (Nordhaus and Shellenberger 2007; Asafu-Adjaye et al. 2015).
} 
technoscience-enabled intensification of the Anthropocene in the pursuit of a thorough decoupling of human societies from biophysical systems. What seems superficially to reproduce at its highest classic dualist purification work, at a closer look results the opposite (not by chance Latour is a member of the Institute!). The hypertrophic role assigned to technoscience, as effectively capable of replacing nature, depicts a total blurring of the human and the nonhuman, the historical record of anthropic transformation of nature being reframed as a testimony that nature is what we want it to be.

As Rommetveit and Wynne remark, the blurring of the world 'out there' and the world as built or buildable - between representing and intervening, between homo depictor and homo faber - is in a sense a reiteration of the case for the reciprocal implication of knowing and making, the genealogy of which goes back at least to Giambattista Vico. However, a peculiar intensification of this case seems to be under way. Current 'engineering' understandings of knowing and acting seem to combine the figure of homo faber with that of the neoliberal homo economicus (an entrepreneurial agent obeying only an internal norm of optimization); ${ }^{2}$ the idea of manipulation of a deterministic world attached to the former and the idea, conveyed by the latter, of a fully pliable task environment (Pellizzoni 2011). Technosciences are conceived no more, or less and less, as entanglements of cognitive and applicative enterprises, where manufactured things are supposed to 'work' because they capture and rearrange the immanent reality of the material world, but because such reality is literally pro-duced, that is 'led forward'. To put things differently, in a slippery, step by step way the traditional idea of science's search for factual truths as glimpses of archetypes according to which effective technology can be built has been increasingly replaced by a ceaseless crafting of prototypes, the truth of which lies in their very existence. ${ }^{3}$ This is possibly the reason why in a variety of fields, from geoengineering to bio and nanotech, one can detect a growing 'love' for uncertainty, indeterminacy and unpredictability as expanding, rather than hampering, the possibility to do things, 'and to do them well' (Taleb 2012: 4).

In this context, the idea of control does not disappear but undergoes a peculiar torsion. If, as Ulrich Beck has argued, technosciences have often engendered 'organized irresponsibility', this was because the full disclosure of truth, the capture of the archetype, worked as an anticipated future retroacting on the present in the form of knowledge provisionally imperfect, hence justifying accidents and 'side effects'. With prototypes, instead, control is conceived as in principle, and not just in fact, local and contingent, the lack of possibility of 'overall' mastery being reframed as systems openness, with resultant unlimited possibilities of individual and collective expansion. This consideration may help to make sense of why, as Gunnarsdottir and Rommetveit note, biometrics has become mandatory independently of any measured improvement in security. There is likely more, here, than mere symbolic politics vis-à-vis feared or actual impotency: the securitization agenda thrives on a politics of indeterminacy where the validation of data (and of the technological devices that produce them: scanners, algorithms etc.) is programmatically tailor made. Moreover, as Delgado and Callen show, a 'prototypical' account of empirical truth is crucial to understanding the logic of hacking and the reason why its relationship with problem-solving is loose. To take shape, 'problems' and 'solutions' need a relatively stable world, as well as relatively stable subjects for whom they are such. Yet bio and e-waste hacks tend to be self-referential experiments, programmatically unfinished, or unfinishable; they can be just prototypes, contingent exemplifications of precarious relationalities.

\footnotetext{
2 The literature on this point, from Foucault's works on neoliberal governmentality downwards, is ample. See, for example, Dardot and Laval (2014).

${ }^{3}$ For Alfred Nordmann (2015) the difference between sciences and technosciences is precisely that the former aim at uncovering archetypes while the latter aim at producing prototypes.
} 


\section{Enquirers, witnesses and lookouts}

All the contributions to this issue probe the notion of public, beyond contentious politics and manipulative strategies for imposing innovation. Deweyan publics, as resulting from the acknowledgment that certain problems overflow the confines of private choice or routine policy-making, seem appropriate venues for tackling technoscientific imaginaries and programs delivered by expert, corporate and political elites, especially in the context of a public opinion increasingly regarded as an obstacle to innovation (Welsh and Wynne 2013). This may explain the relevance recently taken by Dewey, in and beyond STS. Such relevance, however, entails some tension and stretching of his original view.

The material turn in science studies (Woolgar and Lezaun 2013) and beyond moved from a contestation of the 'excessive power granted to language to determine what is real' (Barad 2003: 802), or, as Jepsen and Bertilsson say, from a 'suspicion of sociological analyses focusing solely on human interactions'. However, these authors remark, new materialist outlooks neglect the importance Dewey attributes to human symbolism and social communication. Dealing with the role of imaginaries in eliciting publics may therefore counterbalance current widespread celebrations of the power of things or the liveliness of matter, which may also seem excessive, especially when endowed with emancipatory (or deresponsibilizing?) implications (Pellizzoni 2015). Yet, while both Jepsen and Bertilsson and Gunnarsdottir and Rommetveit address primarily human sense-making of technological devices, Delgado and Callen and O'Riordan, Fotopoulou and Stephens show how public enquiry occurs more and more in and through the very materiality of things. Overall, therefore, the preceding pages confirm the culture/matter tension implied in new ontologies and in practice-oriented accounts of the public.

As for stretching, it is good to remember that the revamp of Dewey's theory of democracy (and especially of The Public and Its Problems) has occurred in the context of the debate over deliberative democracy, seen as a reply to the crisis of the state and of political participation. Deliberative publics have been conceived as a way to restore civic engagement and policy legitimacy and quality vis-à-vis the declining performance of representative democracy. The idea of public enquiry as an answer to a politics dominated by opaque interactions between professional politicians, expert advisors and business lobbyists is of course appealing to STS scholars - technoscience governance offers plenty of evidence of democratic deficits. Yet, for Dewey, the eventual outcome of public enquiries is to feed the institutions of the democratic state. These, in his view, are the only capable of handling in an ordered, inclusive way the instances and insights coming from civil society mobilizations, which find in their 'locality' (in terms of space, time frame and concern) both a strength (one moves from one's own experience) and a limit (generalizing from one's own case is always at risk of blindness and forgetfulness). This gives a measure of the distance that separates Dewey from the present. His was a time when the state was strong and its powers needed to be counterbalanced by the engagement of a lively community. Ours is the time of the retreat of the state or its hollowing out, its subservience to corporate and financial elites. This, as a growing literature testifies, invites to treat with care any case for 'mobilizing' publics, be it a matter of service organization, urban planning or participatory assessment of innovation, especially when such mobilization is presented as a remedy to the alleged inefficiencies of democratic institutions. ${ }^{4}$ As, more in general, current powerful depoliticizing thrusts (Hay 2007) invite to treat with care any case for politics as consisting of (just) problem-solving.

\footnotetext{
${ }^{4}$ A synthesis of critical regards on participation in the field of environment and STS is offered by Tsouvalis and Waterton (2012).
} 
That said, the preceding pages offer confirmations of enduring problems with publics' elicitations and some novel cues. Among the first there is the question of inclusion and exclusion: who is or is not (supposed to be) part of actual or imagined publics; who is us, who is them and who falls outside the picture. In Dewey's terms the question takes the shape of how the 'indirect consequences' of a problem and the involved parties are to be conceived and addressed; how the shift from private to public and from routine to reflection is to be realized. A question to which the American philosopher is the first to recognize there is no clear, undisputable answer - which, incidentally, brings in again contentious politics, supposedly ruled out by public reasoning. Already widely discussed also within STS (e.g. Michael 2009; Felt and Fochler 2010), the issue emerges with clarity in the preceding pages, not only when public events are purposefully designed, as with the tasting of laboratory grown hamburger, but also when people try to make sense of the individual and collective implications of technology, as with biometry and CI.

What is perhaps most interesting in the contributions to this special issue is that they testify to what could be described as a slide from enquiring to witnessing publics. Again, this has to be read through the lenses of intensification. Witnessing publics are anything but new, as historical records and recent chronicles abundantly document, from Boyle and Pasteur to Fleischmann and Pons. We also know that science communication has become increasingly refined, multipurpose and alien from the idea of a linear transfer from inner to outer circles and the general public, with growing recourse to hype, news leakage, early announcement, visual rendering and other ways to gain attention and resources in an increasingly competitive environment. Yet, the preceding pages show that the trend has intensified to a point in which it has possibly become something else.

As a demonstration, the burger event presupposes and produces a witnessing, rather than deliberating, public; yet, a witnessing public of a particular type, of which biometry and CI provide more elusive but no less significant evidence. Their introduction comes from elite decisions in front of which people's reflections - whether they individually or collectively approve, disapprove, or add their own 'ifs and buts' - work to confirm the unavoidable presence of these technologies, amplifying their performative effects. Similarly to the burger case, these publics not only attest to but also actualize the reality of technoscience imaginaries. They are mobilized not so much to validate the soundness of science accounts of phenomena or the working of technical devices, as to make them (more) real. of course, it is always possible for counter-witnessing to rise and for unexpected consequences of mobilizing publics to emerge. Yet, as O'Riordan and colleagues remark, resistance and irony can be seen as part of the game, strengthening the reality effect, rather than challenging it. The basic problem, in all three cases, is the limited agency with which publics allegedly elicited to assess or co-produce technology are ultimately provided. More than active enquirers or passive witnesses, they appear as 'lookouts', marginal accomplices involved in someone else's plot.

This should arguably not apply to DIYbio and e-waste hacking demonstrations - their purpose is precisely to restore an expropriated agency. Yet the relation between precariousness and precarity, on which Delgado and Callen insist, suggests a more nuanced picture. Their account not only confirms that invited and uninvited publics are interwoven (Welsh and Wynne 2013), but indicates also that the emancipatory power of uninvited publics is more fragile than often assumed. Delgado and Callen tell us that working on the precariousness of things, and of the social relations embedded in them, may have the side effect of fostering acceptance of political precarity and of the very logic that determines overproduction and obsolescence. Yet, should we regard this as a side effect, or does it exemplify a central feature of current society? A politics of demonstration shows that 'you can do it yourself', and do it differently, or more cheaply. But does this make any real difference? Better, does it make any difference 
outside a horizon that, not by chance, often assumes a ludic (hence self-referential) dimension, and within which the public, at the very moment that it is mobilized in and through things, becomes more imaginary and phantasmatic than ever? Answering this question is not easy, since hacking interweaves individualistic and public perspectives, subversive, commercial and coping purposes. Yet, hasn't the short circuit between precariousness and precarity, the growing difficulty in telling them apart, to do with the deep, almost anthropological effect that the hegemony of neoliberal accounts of the human and the social has determined over our own self-understanding, and in the framework of which it becomes almost obvious that hacking be hacked (Söderberg and Delfanti 2015) and hackers be hired by those corporate and state organizations against which they had originally mobilized?

\section{Blurring future imaginations}

Imagination is a fundamental resource for scientific enquiry, and imaginaries have always played an important role in the science-society interface. Imagination is linked to symbolism and language, especially the negative modality of linguistic communication. The presence in language of the possibility to add a 'not' to any proposition allows to negate what is and to affirm what is not (Virno 2013). Imagination enables to contest the necessity of what there is and to conceive of what there is not yet, what can be else and different. The fact that imagination is a capacity shared by all human beings, however, may lead to neglecting how power relations and cultural biases extend their reach also to this realm. For example, it is instructive to reflect how machinic imaginaries originating from elite circles have dominated modern accounts of the human, and how these imaginaries have changed according to the technologies, the scientific theories and the ideas of social order characterizing a certain historical moment - from the clockwork to the hydraulic pump, from the metabolic exchange to the cybernetic system, from the computer to the neuronal network (Pellizzoni 2015). In this sense there is nothing properly new in the fact that technosciences and publics imagine, and are imagined by, each other, being affected and affecting the social order. Yet, the category of intensification accounts for how, as Rommetveit and Wynne remark, 'technoscientific imaginations increasingly enter and occupy the institutional, conceptual and cultural spaces between nature and culture, science and society' as a constitutive and performative force.

What the preceding pages offer in this regard, therefore, is to be read in the light of the increasingly promissory character of technoscience narratives and programs, as addressed by plenty of research and attested by mounting discourses and policies about 'anticipatory governance' and 'responsible research and innovation' (Owen et al. 2013). The link between imaginaries and the growing governmental role of indeterminacy emerges clearly in this context. Imagination as the capacity to devise rational developments of the present state of affairs is increasingly replaced by imagination as vision or intuition of latent processes supposed to act as 'game changers' yet not amenable to proper investigation, though being more than just science fiction. To borrow Alfred Nordmann (2014), technoscientific imaginaries increasingly replace 'trivial' futures with 'non-trivial' ones. This is not without consequences on what Rommetveit and Wynne describe as the double-faced character of imaginaries, as disclosing possibilities but also colonizing the future, imposing own accounts of the inevitable or the desirable.

The contributions collected in this issue actually show how the intensified role of imaginaries leads to a change in their character. The best evidence comes from the lab burger, where a striking contrast emerges from the mundane dimension of cooking and eating and the absolute novelty of the object, with its alleged capacity to respond to environmental and 
animalist concerns while maintaining and possibly enhancing existing consumption habits. The awkward combination of 'everyday' and 'sublime' indicates that the distinction between 'trivial' and 'non-trivial' futures is waning, so that the future becomes a matter of construction in a thicker or deeper ontological sense than earlier envisaged or maintained. We are confronted with a sort of pre-emptive affirmativeness of technoscientific promise that gives a non-hyperbolic, quite literal flavour to the quote reported by Rommetveit and Wynne, about technologists and entrepreneurs engaging in 'constructing the future' - or to the (in)famous 'Cheney doctrine', a landmark in neoliberal imagery, whereby future-making is not about rational analysis of probabilities but forceful response to possibilities.

With lesser evidence but no lesser significance the considerations above apply also to biometry, $\mathrm{CI}$ and bio and e-waste hacking. Be it a matter of technological 'resocializing', 'securitizing' or 'empowering' of individuals and collectives, the threshold between mundane and sublime or between trivial and non-trivial futures tends to wane. The performativity of technoscientific imagination seems to be reaching unprecedented levels.

\section{Conclusion}

As said, the contributions to this special issue raise more questions than provide answers, stimulating reflection on the relationship between imagination, publics and technosciences as unfolding in the present historical condition. The intensification of old patterns and recent trends leads to qualitative shifts the character and import of which is not easy to understand. The impression is that we are at a critical moment in a quite literal sense of the word: a moment in which novel potentialities for a democratic governance of technosciences are opening up, but where also novel dominative opportunities are disclosing. Which of these possibilities will be realized arguably depends first of all on how - on what basis and according to what processes - technoscientific problems and solutions are devised. Neither nondualist ontologies nor Deweyan publics or the power of imagination are able by themselves to ensure an innovation respectful of the nonhuman world and responsive to humans' needs and concerns, rather than market logics or elite visions. The picture offered by this issue is of an elusive transition. Faced with fast-evolving technosciences in an increasingly unjust and unequal society, STS scholars are called to sharpen their critical gaze.

\section{References}

Asafu-Adjaye J, Blomqvist L, Brand S et al. (2015) An Ecomodernist Manifesto. http://www.ecomodernism.org/manifesto.

Barad K (2003) Posthumanist performativity: toward an understanding of how matter comes to matter. Signs: Journal of Women in Culture and Society 28(3): 801-831.

Braidotti R (2013) The Posthuman. Cambridge: Polity.

Dardot P and Laval C (2014) The New Way of the World: On Neoliberal Society. London: Verso.

Felt U and Fochler M (2010) Machineries for making publics: inscribing and de-scribing publics in public engagement. Minerva 48 (3): 219-238.

Latour B (2004) Why has critique run out of steam? From matters of fact to matters of concern. Critical Inquiry 30(2): 225-248.

Michael M (2009) Publics performing publics: of PiGs, PiPs and politics. Public Understanding of Science 18(5): 617-631.

Nealon J (2008) Foucault Beyond Foucault. Power and its Intensification since 1984. Stanford, CA: Stanford University Press. 
Nordhaus T and Shellenberger M (2007) Break Through: From the Death of Environmentalism to the Politics of Possibility. New York: Houghton Mifflin.

Nordmann A (2014) Responsible innovation, the art and craft of anticipation. Journal of Responsible Innovation 1(1): 87-98.

Nordmann A (2015) Vanishing friction events and the inverted Platonism of technoscience. In: Bensaude-Vincent B, Loeve S, Nordmann A and Schwarz A (eds.) Research Objects in their Technological Setting. London: Routledge.

Owen R, Bessant J and Heintz M (2013) (eds.) Responsible Innovation. Managing the Responsible Emergence of Science and Innovation in Society. Chichester: Wiley.

Pellizzoni L (2011) Governing through disorder: neoliberal environmental governance and social theory. Global Environmental Change 21(3): 795-803.

Pellizzoni L (2015) Ontological Politics in a Disposable World. The New Mastery of

Nature. Farnham: Ashgate.

Söderberg J and Delfanti A (2015) Hacking hacked! The life cycles of digital innovation. Science, Technology, \& Human Values 40(5): 793-798.

Taleb NN (2012) Antifragile. Things that Gain from Disorder. London: Penguin.

Tsouvalis J, Waterton C (2012) Building 'participation' upon critique: the Loweswater Care Project, Cumbria, UK. Environmental Modelling \& Software 36: 111-121.

Virno P (2013) Saggio sulla negazione. Per una antropologia linguistica. Torino: Bollati Boringhieri.

Welsh I and Wynne B (2013) Science, scientism and imaginaries of publics in the UK: passive objects, incipient threats. Science as Culture 22(4): 539-565.

Woolgar S and Lezaun J (2013) The wrong bin bag: a turn to ontology in science and technology studies? Social Studies of Science 43(3): 321-340.

Luigi Pellizzoni is associate professor of sociology at the Department of Political and Social Sciences of the University of Trieste, Italy. His interests focus on the intertwining of environmental, technoscientific and political change. Recent publications include Neoliberalism and Technoscience. Critical Assessments, Ashgate, 2012 (with Marja Ylönen) and Ontological Politics in a Disposable World. The New Mastery of Nature, Ashgate 2015. 